\title{
Emerging challenges in the evaluation of fever in cancer patients at risk of febrile neutropenia in the era of COVID-19: a MASCC position paper
}

\author{
Tim Cooksley ${ }^{1}$ (D) Carme Font $^{2} \cdot$ Florian Scotte $^{3} \cdot$ Carmen Escalante $^{4} \cdot$ Leslie Johnson $^{5} \cdot$ Ronald Anderson $^{6}$. \\ Bernardo Rapoport ${ }^{7}$
}

Received: 3 September 2020 / Accepted: 18 November 2020 / Published online: 23 November 2020

(C) Springer-Verlag GmbH Germany, part of Springer Nature 2020

\begin{abstract}
Patients with cancer are at higher risk of more severe COVID-19 infection and have more associated complications. The position paper describes the management of cancer patients, especially those receiving anticancer treatment, during the COVID-19 pandemic. Dyspnea is a common emergency presentation in patients with cancer with a wide range of differential diagnoses, including pulmonary embolism, pleural disease, lymphangitis, and infection, of which SARS-CoV-2 is now a pathogen to be considered. Screening interviews to determine whether patients may be infected with COVID-19 are imperative to prevent the spread of infection, especially within healthcare facilities. Cancer patients testing positive with no or minimal symptoms may be monitored from home. Telemedicine is an option to aid in following patients without potential exposure. Management of complications of systemic anticancer treatment, such as febrile neutropenia (FN), is of particular importance during the COVID-19 pandemic where clinicians aim to minimize patients' risk of infection and need for hospital visits. Outpatient management of patients with low-risk FN is a safe and effective strategy. Although the MASCC score has not been validated in patients with suspected or confirmed SARS-CoV-2, it has nevertheless performed well in patients with a range of infective illnesses and, accordingly, it is reasonable to expect efficacy in the clinical setting of COVID-19. Risk stratification of patients presenting with FN is a vital tenet of the evolving sepsis and pandemic strategy, necessitating access to locally formulated services based on MASCC and other national and international guidelines. Innovative oncology services will need to utilize telemedicine, hospital at home, and ambulatory care services approaches not only to limit the number of hospital visits but also to anticipate the complications of the anticancer treatments.
\end{abstract}

Keywords COVID-19 · Cancer · Febrile neutropenia · Granulocyte colony-stimulating factor (G-CSF) · Telemedicine

Tim Cooksley

cooks199@hotmail.com

1 Department of Acute Medicine and Critical Care, The Christie, Wilmslow Road, Manchester, UK

2 Hospital Clinic de Barcelona, Barcelona, Spain

3 Interdisciplinary Cancer Course Department (DIOPP), Gustave Roussy Cancer Institute, Villejuif, France

4 MD Anderson Cancer Center, Houston, TX, USA

5 MASCC, Toronto, Canada

6 University of Pretoria, Pretoria, South Africa

7 The Medical Centre of Rosebank, Johannesburg, South Africa

\section{Introduction}

In December 2019, COVID-19 (Corona Virus Disease-2019) infections were first noted in Wuhan, China. Since then it has spread rapidly throughout the world and was declared a pandemic by the World Health Organization in March 2020. The cause of COVID-19 is a novel coronavirus, severe acute respiratory syndrome coronavirus 2 (SARS-Cov-2), which likely originated in chrysanthemum bats that served as a viral reservoir and intermediary host prior to human transmission [1]. The virus has shown itself to be highly contagious with rapid human-to-human transmission and is associated with significant morbidity and mortality [2]. Unfortunately, there are currently no medications or vaccines to prevent infection and few pharmacologic agents that have shown significant improvement in the overall disease trajectory for the majority 
of infected patients. Therefore, prevention of COVID-19 infection is imperative, especially in vulnerable populations. Populations at higher risk for infection and with poorer outcomes include cancer patients. Patients with malignancy have immunosuppression both from the malignancy per se and from the effects of treatment, especially those patients on active cancer treatment within the 30 -day period prior to COVID-19 infection [3]. Importantly, recent publications have noted that patients with cancer are at higher risk of more severe COVID-19 infection and have more associated complications. In addition, a cancer diagnosis is also associated with a higher risk of death or intensive care unit (ICU) admission $[3,4]$. Table 1 serves as a framework in respect of the new scenarios and main concerns that have emerged during the COVID-19 pandemic regarding the care of cancer patients at risk for developing febrile neutropenia (FN). It indicates the challenges as well as the opportunities for promoting the active participation of clinicians and patients to support advanced care planning and long-term transformation of models of healthcare. The objective of this manuscript is to review the current literature and present recommendations, mostly based on consensus on the management of cancer patients, especially those receiving anticancer treatment, during the COVID-19 pandemic.

\section{COVID-19 and cancer}

Outcomes in patients with cancer who contract SARS-CoV-2 are of significance in terms of both managing the acute COVID-19 presentation and planning cancer therapies. There has been an expectation that cancer patients may be at higher risk of complications due to immunosuppression, especially from chemotherapy and other associations with malignancy, including increased age and co-morbidities. Studies examining outcomes in patients with SARS-CoV-2 to date have been largely retrospective with small numbers of patients and have produced variable conclusions reflecting the heterogeneity of the cancer types, the nature of the SARS-CoV-2 illness, and the clinical settings in which these patients have been managed.

A prospective study of 1590 COVID-19 patients in China reported that patients with cancer had a significantly increased

Table 1 Challenges and opportunities related to the prevention and management of febrile neutropenia (FN) during the COVID-19 pandemic

\begin{tabular}{|c|c|c|}
\hline Emerging scenario & Arising concerns & Actions/opportunities/future directions \\
\hline $\begin{array}{l}\text { Overwhelmed health } \\
\text { systems: } \\
\text { - Rationing policies } \\
\text { - Shortage of healthcare } \\
\text { resources }\end{array}$ & $\begin{array}{l}\text { Delay or interruption of } \\
\text { standard } \\
\text { cancer care }\end{array}$ & $\begin{array}{l}\text { Multidisciplinary work-up by bioethicists, clinicians, } \\
\text { and healthcare providers aimed at maximizing health results } \\
\text { Development of written consensus criteria integrating } \\
\text { clinical, legal, and ethical aspects: } \\
\text { - Reordenation of non-COVID-19, non-urgent hospital services } \\
\text { - ICU admission and use of other potentially life-preserving resources } \\
\text { - Active participation of oncologists at each institution in order } \\
\text { to tailor optimal benefit/risk assessment for each individual patient, } \\
\text { promote advance care planning discussions and individualize } \\
\text { decisions regarding clinical trials }\end{array}$ \\
\hline $\begin{array}{l}\text { Risk of SARS-CoV-2 } \\
\text { transmission: } \\
\text { - Need for physical distance } \\
\text { - Lockdown policies } \\
\text { - Transportation limitations } \\
\text { - Lack of accompaniment for } \\
\text { vulnerable patients }\end{array}$ & $\begin{array}{l}\text { Risk of COVID-19 infection } \\
\text { spread } \\
\text { in healthcare facilities and } \\
\text { amongst healthcare workers } \\
\text { Need to reduce the number } \\
\text { of face-to-face visits to the } \\
\text { minimum as possible }\end{array}$ & $\begin{array}{l}\text { COVID-19 testing to: } \\
\text { - Symptomatic patients. Routine screening questioning } \\
\text { to all patients coming to outpatient cancer clinics } \\
\text { - Patients admitted to hospital or other invasive procedures } \\
\text { Development and promotion of alternative outpatient healthcare interventions:- } \\
\text { Telemedicine: medical counseling, remote screening, and monitoring, } \\
\text { patient-reported outcome measures, nurse navigator management } \\
\text { - Home hospitalization programs: blood testing, parenteral anticancer and } \\
\text { antimicrobial treatments }\end{array}$ \\
\hline $\begin{array}{l}\text { Greater clinical complexity } \\
\text { in daily care }\end{array}$ & $\begin{array}{l}\text { Optimal FN prevention } \\
\text { Areas of uncertainty }\end{array}$ & $\begin{array}{l}\text { Expanded use of G-CSF } \\
\text { Shared decision-making specific worksheets and informed consent on whether } \\
\text { or not to postpone or interrupt ablative chemotherapy on a patient-by-patien } \\
\text { basis considering: } \\
\text { - Curative vs palliative settings } \\
\text { - Co-morbidities } \\
\text { - Value-based care and preferences } \\
\text { Further research needed: patient acceptance and engagement, inequalities, barrier } \\
\text { in access, outcomes measures and quality of life, research regarding the new } \\
\text { models of cancer care }\end{array}$ \\
\hline
\end{tabular}

$G$-CSF, growth colony-stimulating factors; $F N$, febrile neutropenia; $S A R S-C o V-2$, severe acute respiratory syndrome coronavirus 2 
risk (39\% vs. $8 \%$ ) of poor outcomes (invasive ventilation or death) [3]. However, only 18 patients in the study had cancer with a range of malignancies. Another small Chinese retrospective study of 28 cancer patients suggested poor outcomes, with $53.6 \%$ of patients having severe disease and a mortality rate of $28.6 \%$ [4].

An Italian national registry study recorded if patients had been treated for cancer within the last 5 years and reported that $16.5 \%$ of COVID-19 deaths had a history of cancer [5]. The percentage of patients undergoing active cancer management is unknown. Importantly, however, $4.7 \%$ of these patients were not initially admitted with suspected COVID19. A UK prospective observational study of 800 patients with active cancer and symptomatic COVID-19 reported a majority of patients $(52 \%)$ had a mild clinical illness, and $28 \%$ of patients died [6]. Older cancer patients, the presence of other co-morbidities, and being male were significant determinants of outcome. There was, however, no evidence to support that patients being treated with anticancer therapies had poorer outcomes compared to those not on active treatment. A retrospective analysis of 309 patients presenting with COVID-19 and cancer in New York also found that recent cytotoxic chemotherapy was not associated with adverse outcomes [7].

There is emerging evidence that those with hematological and thoracic malignancies have worse outcomes from COVID-19. A study from Wuhan comparing 105 cancer patients to 536 age-matched patients without cancer demonstrated more severe presentations in patients with hematological malignancies, lung cancer, and metastatic disease [8]. A case series of 35 UK patients with hematological malignancies and COVID-19 reported a mortality rate of $40 \%$ [9]. Analysis of 200 thoracic cancer patients with COVID-19 in the TERAVOLT registry revealed a hospitalization rate of $76 \%$, with a mortality rate of $33 \%$ [10]. Only $6.5 \%$ of the patients were admitted to an ICU.

The rapidly evolving nature of the global COVID-19 pandemic, the lack of any major multinational studies in patients with cancer, variable results in published studies, and the lack of data of many patients who have had asymptomatic or mild illnesses and not tested for SARS-CoV-2 and managed in community settings may impact guidance on the evolution of SARS-CoV-2 in patients with cancer. This necessitates consideration of adaptations to the current neutropenic sepsis and low-risk febrile neutropenia pathway guidelines but with an expectation that the core principles of their management remain apposite.

\section{Clinical work-up and screening for COVID-19 in cancer patients}

The most frequent symptoms noted in COVID-19-infected patients include fever, cough, shortness of breath, or difficulty in breathing. Other symptoms described include myalgias, sore throat, nasal congestion, loss of smell or taste, and diarrhea. Some patients may be completely asymptomatic, albeit COVID-19 positive. Patients with any of these symptoms should call their health care provider prior to visiting the clinic or hospital for further direction.

It may be challenging to differentiate COVID-19 infection from other viral infections, including influenza and even allergies. However, if there is any concern regarding the diagnosis, testing is advised. Some factors that may be helpful in discerning between COVID-19 infection, influenza, and allergies include the follows: COVID-19 symptoms usually occur between 2 to 14 days following exposure; in distinction to COVD-19, allergies often cause sneezing associated with itchy and watery red or swollen eyes, itchy nose with either nasal discharge, or congestion and usually a history of environmental allergies. Influenza may be difficult to distinguish from COVID-19 infection since there is a significant overlap of symptoms, and testing may often be necessary. Immunization against influenza is vital during the COVID19 pandemic, especially as local "flu seasons" approach.

Dyspnea is a common emergency presentation in patients with cancer with a wide range of differential diagnoses, including pulmonary embolism, pleural disease, lymphangitis, and infection of which SARS-CoV-2 is now a pathogen to be considered. Moreover, appropriate clinical evaluation and COVID19 testing should be performed in the setting of suspected "incidental COVID-19 infection" in asymptomatic (or paucisymptomatic) patients attending for a routine follow-up CT staging when images may be consistent with COVID-19.

Screening interviews to determine whether patients may be infected with COVID-19 are imperative to prevent the spread of infection, especially within healthcare facilities. Those with suspected COVID-19 infection should be sent for testing. This includes responses indicative of at least one symptom including exposure risk, fever, and respiratory symptoms without other known causes. Patients with significant respiratory symptoms or requiring home oxygen need urgent evaluation and should be referred to an emergency facility. The emergency facility should be alerted before the patient's arrival, thus enhancing the ability to respond appropriately in the setting of ongoing patient isolation and implementation of patient and healthcare provider safety precautions. Patients with only travel or contact exposure and no symptoms should be educated regarding monitoring for symptoms and may not need testing if they are not entering a healthcare facility. Asymptomatic patients that may be considered for testing include those who are new to a facility, those discharged from a nursing or long-term acute care facility, those who are in inpatient admission, those who will undergo surgery or other invasive procedures, those who will be initiating radiotherapy, those who will undergo stem cell transplant, cellular product 
infusion, or induction chemotherapy for acute leukemias, and those who will undergo donor screening.

Cancer patients testing positive with no or minimal symptoms may be monitored from home. Telemedicine has been widely utilized during the pandemic and is an option to aid in following patients without potential exposure. Generally, patients should be quarantined according to their national public health guidance regulations. Patients should wear masks and be isolated in an area of the medical facility that is separate from patients without COVID-19 infection, as well as from those requiring an urgent ambulatory treatment such as chemotherapy for a fast-growing malignancy or a procedure that cannot be postponed. Appropriate environmental protection measures such as special airflow handling should be available in treatment rooms housing COVID-19 positive patients.

Although serology testing for COVID-19 continues to develop, it is not routinely available. Positive serology testing indicates an immune response but does not definitively determine whether a person is immune. It is unknown whether the presence of antibodies determines protective immunity and for how long that protection may last if present. Earlier trials suggest that approximately $50 \%$ of immunocompetent COVID-19 patients will develop antibodies at 7 days postexposure and the majority by 14 days; however, immunocompromised individuals may mount no response or a partial response [11].

\section{Management of febrile neutropenia during COVID-19}

Supportive care is an essential part of cancer treatment [12]. Management of complications of systemic anticancer treatment, such as febrile neutropenia (FN), is of particular importance during the COVID-19 pandemic where clinicians aim to minimize patients' risk of infection and need for hospital visits.

Infections are a significant cause of morbidity and mortality in cancer patients [13]. During the COVID19 pandemic, it is crucial to assess the patient's quantitative and qualitative immune defects and stratify the risk for specific pathogens in the context of the patient's clinical history, the physical examination, and radiological and laboratory results.

There are multiple risk factors for infections that may be present in a cancer patient. These factors are different in patients with solid tumors as opposed to hematological malignancies $[14,15]$. Concomitant infective illnesses are prevalent in patients with SARS-CoV-2 infection, and patients with FN must have a thorough examination and work-up for these. For example, COVID-19 colitis is an important presentation in patients with neutropenia and gastrointestinal translocation of infective pathogens is almost inevitable.
In solid malignancies, the presence of anatomical abnormalities is significant. Tumors that overgrow their blood supply become necrotic and infected. Different solid tumors are associated with various infections. Patients with head and neck tumors, with associated erosion through the neck and floor of the mouth, are predisposed for anaerobic infection. Those with advanced esophageal cancer, complicated by an obstruction, have an increased the risk of aspiration pneumonia. Endobronchial lung tumors are associated with chronic inflammation and recurrent post-obstructive infections [16]. Intra-abdominal tumors obstructing the genitourinary or hepato-biliary tracts may result in severe urinary tract infections or cholangitis $[17,18]$. Tumor invasion of the colonic mucosa may also predispose for local abscess formation by enteric flora [19]. Locally advanced breast cancer is associated with an increased risk of Staphylococcus aureus abscess formation [20].

Lymphoproliferative disorders are frequently associated with hypo-gammaglobulinemia due to the disease and the treatment [21]. Patients with hairy cell leukemia have a higher incidence of unusual infections, including those caused by mycobacteria and Listeria monocytogenes probably due to chronic neutropenia and monocytopenia [22]. Patients with untreated Hodgkin's disease have significant immune dysfunction, which persists in the majority of long-term Hodgkin's disease survivors. These patients are at increased risk for toxoplasmosis, pneumocystis, nocardiosis, cryptococcus, and mycobacterial infections, as well as herpes zoster [23].

The risk of invasive fungal infections such as aspergillosis is also directly related to the duration of neutropenia, with aspergillosis found to be uncommon in leukemic patients when the duration of neutropenia was less than 2 weeks. On the other hand, after day 14, the risk of fungal infections increased proportionally in relation to the duration of neutropenia. Fungal infections are also a significant cause of mortality in patients with persistent neutropenia in the setting of bone marrow transplantation [24].

\section{Evaluation and management of febrile neutropenia}

Neutropenic fever is defined as a single oral temperature of higher than $38.3^{\circ} \mathrm{C}\left(101{ }^{\circ} \mathrm{F}\right)$ or greater than or equal to $38.0{ }^{\circ} \mathrm{C}$ over at least $1 \mathrm{~h}$. The absolute neutrophil count (ANC) should be less than $500 / \mu \mathrm{L}$ or less than $1000 / \mu \mathrm{L}$ with a predicted rapid decline to less than $500 / \mu \mathrm{L}$. Initial evaluation of patients with FN consists of a complete clinical history and physical examination. The initial laboratory evaluation should include the following: complete blood cell and differential count; serum chemistry, including liver function test; two sets of blood cultures from different sites (including from each 
lumen of the central venous catheter); a urine culture; and a chest radiograph. In those in whom COVID-19 is clinically suspected, there should be a low threshold to perform a CT thorax. FN should be regarded as a medical emergency, and prompt initiation of empiric antibiotics should be initiated without delay. Following the initial physical examination, it is critical to re-evaluate the patient at least daily to monitor the response to therapy and to identify evolving signs of infection that were not present during the initial evaluation $[15,25,26]$.

Cancer patients with FN could have an established or an occult infection, and bacteremia is only documented in approximately a quarter of these patients. Additionally, patients with FN can present with an occult infection and may not have symptoms or signs and the clinical history may be limited to fever following chemotherapy treatment $[15,25,26]$.

Prompt initiation of empiric antibiotics is indicated due to the potential for rapid progression to severe sepsis. With the availability of highly effective monotherapy regimens for FN, initial empiric duo-therapy regimens are currently recommended for unstable patients or in the setting of health care establishments in which multidrug-resistant pathogens are frequently encountered [27]. Meta-analyses have revealed that the use of combination antibiotics with broad-spectrum betalactam antibiotics with anti-pseudomonal activity and an aminoglycoside resulted in increased toxicity and similar survival.

The addition of aminoglycoside antibiotics (which were formerly the standard of care) should be limited to hemodynamically unstable patients [28]. Ciprofloxacin is an alternative to aminoglycoside antibiotics in this setting (part of a combination regimen). This antimicrobial agent should be considered in patients with a reduction in kidney function [29].

\section{Outpatient management of febrile neutropenia}

Outpatient management of patients with low-risk FN is a safe and effective strategy [30-34]. MASCC has pioneered work in this field and has developed a risk-assessment model that includes seven independent prognostic variables each with an assigned integer value [33]. A MASCC risk index equal to or greater than 21 identifies low-risk patients with a positive predictive value of $91 \%$ (specificity $68 \%$ and sensitivity $71 \%$ ) of developing serious complications [30]. Patients with a MASCC risk index greater than 21 should be considered candidates for outpatient antibiotic therapy for FN [30, 34]. The MASCC score has been prospectively validated in several settings, and its use is broadly recommended as a simple and easy strategy to apply as a triaging tool. Although the MASCC score has not been validated in patients with suspected or confirmed SARS-CoV-2, it has nevertheless performed well in patients with a range of infective illnesses and, accordingly, it is reasonable to expect efficacy in the clinical setting of
COVID-19. The MASCC score is validated in those with hematological malignancies but given the poorer outcome in these patients with COVID-19, the threshold for outpatient management should be higher. Risk scores should be used in conjunction with clinical judgement for the identification of patients suitable for outpatient management of neutropenic fever (Table 2) [35].

The benefits of emergency outpatient care include admission avoidance, reducing pressure on often overcrowded and overstretched emergency departments, cost savings, reduced risk of nosocomial infections, and improved patient experience and satisfaction [36-38]. Adherence to these measures is particularly important during the COVID-19 pandemic. Furthermore, late presentation of patients with FN remains a significant risk, sometimes driven by concerns of prolonged hospital admission especially during the current pandemic; in this context a greater awareness of, and access to, outpatient options may help mitigate this risk [39].

The challenges of delivering emergency outpatient care for low-risk FN patients are not insignificant and include staffing requirements, care packages, and transport/geographical issues. Moreover, there needs to be good communication between emergency care providers and oncology clinics to facilitate this management [40]. Risk stratification of patients presenting with $\mathrm{FN}$ is a vital tenet of the evolving sepsis and pandemic strategy, necessitating access to locally formulated services based on MASCC and other national and international guidelines. A proposed algorithm for triaging cancer patients presenting with FN in the era of COVID-19 is shown in Fig. 1.

\section{Expanded use of granulocyte colony-stimulating factor during the COVID-19 pandemic}

Supportive care interventions play a crucial role in decreasing the risk of cancer treatment complications, which, during the COVID-19 pandemic, is of particular importance to reduce cancer patient interactions with healthcare workers. In the curative setting, the main goal of cancer treatment is to maintain treatment dose intensity in order to attain a cure and avoid hospitalization due to FN. On the other hand, in the palliative setting, the main aim of supportive care interventions is to avoid hospitalization due to FN. The use of prophylactic granulocyte colony-stimulating factor (G-CSF) decreases the incidence of FN and infection-related mortality. Prophylactic GCSF also enables the relative dose intensity of chemotherapy to be maintained [41]. All guidelines currently recommend prophylactic use of G-CSF when the overall risk of FN from the prescribed chemotherapy regimen is $\geq 20 \%$ [25, 42]. These guidelines highlight the issue that primary prophylaxis with G-CSF is more effective than using G-CSF after an 
Table 2 Clinical criteria to be considered before the early discharge of cancer patients with $\mathrm{FN}$ in the era of COVID-19 infection
Reasons for hospital admission in cancer patients with FN

Suspicion of a potentially life-threatening infection

Grade $\geq 2$ anticancer drug toxicities

Other common complications in cancer patients requiring inpatient care up to stabilization

Geographical and psychosocial conditions

Related to COVID-19 infection
- Direct or indirect signs of sepsis: chills, fever, tachycardia, tachypnea, arterial hypotension, hypoperfusion

- Urinary infection/urinary obstruction

- Pneumonia/obstructive pneumonitis/hypoxemia/hypercapnia

- Abdominal infection: cholangitis (biliary stent), cholecystitis, diverticulitis, appendicitis, typhlitis

- Catheter infection

- Central nervous system infection: confusion, seizures

- Previous hospital admission/multi-resistant infection. Antibiotics used for empirical outpatient management

- Digestive: unable to swallow oral medication, oral mucositis, diarrhea, hepatitis, pancreatitis

- Hematologic: thrombocytopenia, anemia, profound neutropenia ANC $\leq 100 / \mathrm{mL}$ or expected grade 4 neutropenia $\leq 500 / \mathrm{mL}$ duration $\geq 7$ days

- Renal impairment. Clinically relevant electrolyte abnormalities

- Cardiovascular symptoms: syncope, arterial hypotension, accelerated arterial hypertension, heart failure, angina, arrhythmias

- Venous thromboembolism/active clinically relevant bleeding

- Malignant intestinal obstruction

- Pleural and/or pericardial effusions, superior vena cava syndrome

- Pain: parenteral opioid titration, bone fractures

- Neurological symptoms: delirium, brain metastasis, leptomeningeal carcinomatosis, presence, or concern for spinal cord compression

- Need for emergent radiation therapy

- Any other supportive and palliative care need for intervention due to cancer progression, performance status decline, frailty, or any concern based on a case by case characteristics and individual clinical judgement of treating physicians

- Distance $>1 \mathrm{~h}$ driving from home to hospital

- Inadequate psychosocial profile for adherence to oral antimicrobial treatment and subsequent follow-up visits

- Respiratory symptoms: hypoxemia requiring supplemental oxygen, acute respiratory distress

- Venous thromboembolism/disseminated intravascular coagulation/Thrombocytopenia/bleeding

- Multiorgan dysfunction/failure (kidney, liver, heart, central nervous system) due to direct viral endothelial injury/microvascular thrombosis/cytokine release syndrome

- Bacterial infection/septic shock episode of FN (secondary prophylaxis) or dose-delay episode due to myelosuppression. It is essential to point out that more than half of these FN episodes occur following the first cycle of chemotherapy [43].
Supportive care interventions reducing the risk of neutropenic complications include preventing neutropenia and reducing the FN risk threshold for G-CSF to include lowerrisk patients independent of the risk factors, thereby enabling administration of $\mathrm{G}-\mathrm{CSF}$ to more patients receiving 
Telemedicine or Personal assessment at the ED room

Triage of cancer patients with fever at risk of FN (myeloablative chemotherapy within the last 6 weeks)

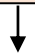

Individual room with contact / respiratory isolation / PPE use - Vital signs - Draw blood pretreatment samples

Confirm Grade 4 neutropenia (ANC $<500 / \mathrm{mL}$ ) or Grade 3 neutropenia (ANC 500-1000/mL) expected to fall to Grade 4

Systematic medical interview and physical exam to assess clinical severity and rule out possible foci of infection including COVID-19 PCR testing

Administer first dose of antimicrobial treatment within 1 hour

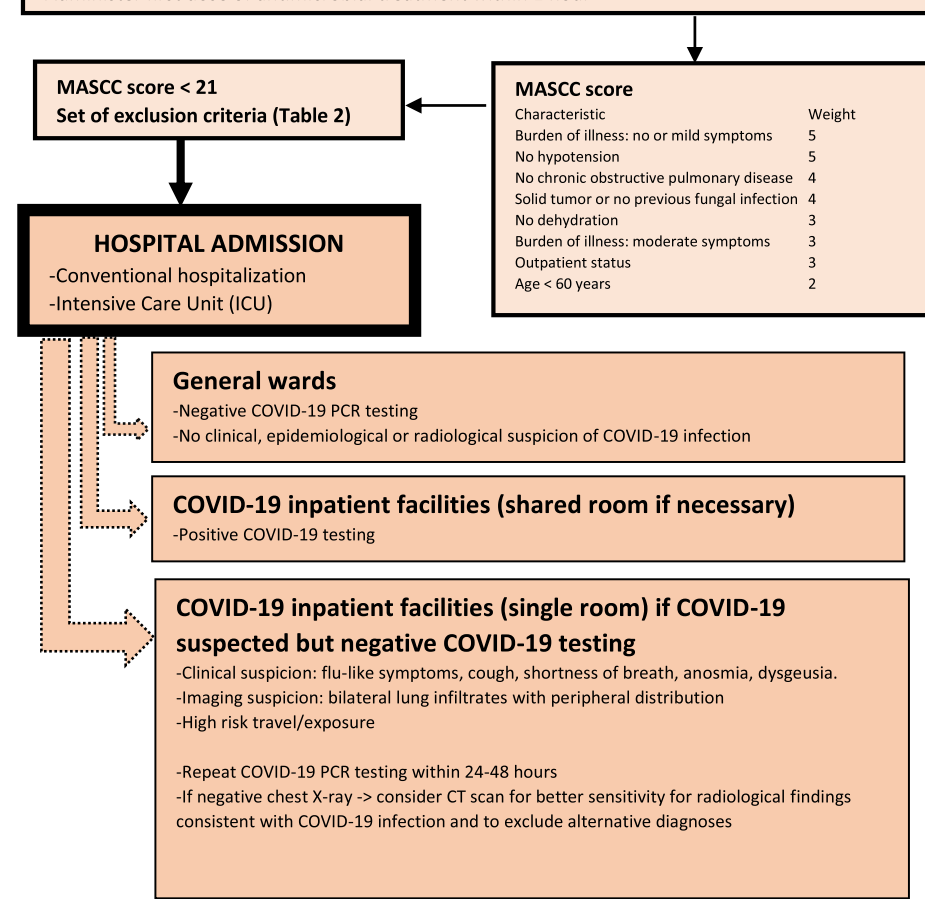

Fig. 1 Flowchart - triage of cancer patients at risk of FN in the era of COVID-19 pandemics

chemotherapy. During the COVID-19 pandemic, long-acting G-CSF (e.g., pegfilgrastim) may be used to provide convenience, neutropenia prophylaxis and to reduce contact with healthcare professionals [44]. Prophylactic antibiotics can be used to reduce infections in neutropenic patients. ASCO/ IDSA guidelines recommend that antibacterial and antifungal prophylaxis be restricted to patients at high risk of infection, including patients who are expected to have profound, protracted neutropenia, which is defined as $<100$ neutrophils $/ \mu \mathrm{L}$ for $>7$ days or other risk factors $[33,45]$. In patients with solid tumors, antibacterial and antifungal prophylaxis would generally not be indicated when G-CSF prophylaxis effectively reduces the magnitude and duration of neutropenia. Although the usage of fluoroquinolone prophylaxis in high-risk neutropenic patients is regarded as the standard of care, the emergence of resistance remains a significant concern $[33,46]$.

The recently updated ESMO guidelines recommend that patients with solid tumors receive chemotherapy with noncurative intent, a setting in which regimens less likely to induce FN should be considered [47]. ASCO, ESMO, and NCCN updated their recommendations to include expanded use of prophylactic G-CSF to include patients receiving chemotherapy regimens that have an intermediate risk of FN (>
$10 \%$ ) [47-50]. The NCCN recommends self-administration of G-CSF or the use of long-acting agents to reduce the frequency of outpatient visits [50]. ASCO recommendations include telemedicine or telephone calls to evaluate the febrile patient and to establish whether a particular patient requires assessment in the clinic or emergency department $[48,49]$.

In the case of patients with known FN, standard guidelines for neutropenic patients should be followed, regardless of COVID-19 status. Rapid COVID-19 testing should be used to determine the level of personal protective equipment (PPE) necessary for caregivers, as well as the appropriate location for continued care.

In the absence of rapid testing, the patient should be managed following standard guidelines for patients with neutropenic fever under the presumption of COVID-19 infection. The crucial role of extended access to G-CSF in cancer is to prevent neutropenia and maintain anticancer treatment dose intensity. There is no evidence to support advocating the use of G-CSF at the time of acute neutropenic sepsis [51].

Regarding neutropenia prophylaxis in cancer patients with COVID-19, ESMO guidelines recommend considering extended usage of G-CSF after chemotherapy to lower the risk of FN [48]. ESMO guidelines also warn of the theoretical possibility that G-CSF may cause added harm in patients with 
active COVID-19 due to the possibility of increasing production of pro-inflammatory cytokines; however, this concern does not outweigh the benefit of treatment [48].

\section{Opportunities for the development of new models of care, including e-health and digital systems}

A modern approach for health care control is the provision of remote monitoring using patient-reported outcomes measures. Such a program has already produced valuable results with respect to regulating chemotherapy-induced toxicity, as well as survival benefits [52-54]. The viral pandemic has shown the importance of applying these modern strategies not only in order to limit the number of hospital visits but also to anticipate the complications of the anticancer treatments. Moreover, telemedicine allows patients to be efficiently screened, enabling distant patient-centered care, while preventing exposure. Clinical and biological monitoring through digital solutions combined with nurse navigators allows anticipation and prevention of adverse downstream consequences [55]. Telemonitoring is well suited in the context COVID-19 and organizations that have already invested in telemedicine ensure that patients with COVID-19 receive the appropriate care [56].

Together with virtual healthcare platforms, hospital at home $(\mathrm{HaH})$ and ambulatory care programs are important alternatives to conventional hospitalization. These are key tenets in ensuring the safety and sustainability of acute care and oncology services. Individualized management of acute cancer presentations is essential in emergency oncology services so it can mirror routine cancer care [57]. The spectrum of emergency cancer presentations is increasing and includes not only FN but also incidental pulmonary embolism, indwelling line infections, and chemotherapy-related acute kidney injury, which can be risk assessed for care in these settings [57-59].

These models offer the opportunity to integrate palliative and supportive care with oncology and acute services. This may facilitate improved access of patients to expertise in cancer care, as well as immediate management of the complications of cancer treatment with the goal of preventing downstream complications and future emergency presentations [38, 60]. Moreover, the health crisis that has arisen from the COVID-19 pandemic may engender rethinking of, and enhance ethical approaches in, the care of cancer patients [61], as well as improved communication and education of patients that will lead to tailoring of value-based shared decisionmaking strategies in the era of precision medicine. Modeling and innovations in oncology services clearly need integration of expert acute care and supportive and palliative care services to provide high quality, personalized, and sustainable oncology care during the COVID-19 pandemic and beyond.

Author contributions All authors contributed equally, discussed, and agreed on position paper.

Data availability No data or code availability was used in this position paper.

\section{Compliance with ethical standards}

Conflict of interest Dr. Rapoport reports grants, personal fees, nonfinancial support, and advisory boards and is a speaker engagement from Sandoz and speaker engagement from Amgen South Africa, during the conduct of the study. Dr. Scotte reports grants, personal fees, and other from AMGEN; personal fees and other from Mylan; grants, personal fees, and other from Roche; personal fees and other from Mundipharma; personal fees and other from Leo Pharma; personal fees and other from Tesaro; personal fees and other from Helsinn; personal fees and other from Tilray; personal fees and other from Vifor Pharma; personal fees and other from Pfizer; personal fees and other from BMS; and personal fees and other from Pierre Fabre Oncology, outside the submitted work. The other authors declare no conflicts of interest.

No ethics approval is required for this position paper.

There is no patient consent for participation or publication relevant to this position paper.

\section{References}

1. Del Rio C, Malani PN (2020) COVID-19-new insights on a rapidly changing epidemic. JAMA 323:1339-1340

2. Huang C, Wang Y, Li X, Ren L, Zhao J, Hu Y, Zhang L, Fan G, Xu J, Gu X, Cheng Z, Yu T, Xia J, Wei Y, Wu W, Xie X, Yin W, Li H, Liu M, Xiao Y, Gao H, Guo L, Xie J, Wang G, Jiang R, Gao Z, Jin Q, Wang J, Cao B (2020) Clinical features of patients infected with 2019 novel coronavirus in Wuhan, China. Lancet 395:497-506

3. Liang W, Guan W, Chen R, Wang W, Li J, Xu K, Li C, Ai Q, Lu W, Liang H, Li S, He J (2020) Cancer patients in SARS-CoV-2 infection: a nationwide analysis in China. Lancet Oncol 21(3):335337

4. Zhang L, Zhu F, Xie L, Wang C, Wang J, Chen R, Jia P, Guan HQ, Peng L, Chen Y, Peng P, Zhang P, Chu Q, Shen Q, Wang Y, Xu SY, Zhao JP, Zhou M (2020) Clinical characteristics of COVID-19infected cancer patients: a retrospective case study in three hospitals within Wuhan, China. Ann Oncol 31:894-901

5. Trapani D, Marra A, Curigliano G (2020) The experience on coronavirus disease 2019 and cancer from an oncology hub institution in Milan, Lombardy region. Eur J Cancer 132:199-206

6. Lee L, Cazier J, Starkey T et al; UK Coronavirus Cancer Monitoring Project Team (2020) COVID-19 prevalence and mortality in patients with cancer and the effect of primary tumour subtype and patient demographics: a prospective cohort study. Lancet Oncol 21(10):1309-1316

7. Jee J, Foote MB, Lumish M et al (2020) Chemotherapy and COVID-19 outcomes in patients with cancer [published online ahead of print]. J Clin Oncol 2020:JCO2001307

8. Dai M, Liu D, Liu M, Zhou F, Li G, Chen Z et al (2020) Patients with Cancer Appear More Vulnerable to SARS-CoV-2: A Multicenter Study during the COVID-19 Outbreak. Cancer Discov 10(6):783-791 
9. Aries J, Davies J, Auer R et al (2020 (Epub ahead of print)) Clinical outcome of coronavirus disease 19 in haemato-oncology patients. Br J Haematol 190:e64-e67

10. Garassino M, Whisenant J, Huang L, Trama A, Torri V, Agustoni F, Baena J, Banna G, Berardi R, Bettini AC, Bria E, Brighenti M, Cadranel J, de Toma A, Chini C, Cortellini A, Felip E, Finocchiaro G, Garrido P, Genova C, Giusti R, Gregorc V, Grossi F, Grosso F, Intagliata S, la Verde N, Liu SV, Mazieres J, Mercadante E, Michielin O, Minuti G, Moro-Sibilot D, Pasello G, Passaro A, Scotti V, Solli P, Stroppa E, Tiseo M, Viscardi G, Voltolini L, Wu YL, Zai S, Pancaldi V, Dingemans AM, van Meerbeeck J, Barlesi F, Wakelee H, Peters S, Horn L, TERAVOLT investigators (2020 (epub ahead of print)) COVID-19 in patients with thoracic malignancies (TERAVOLT): first results of an international, registry-based, cohort study. Lancet Oncol 21:914-922

11. Tang Y, Schmitz JE, Persing DH et al (2020) Laboratory diagnosis of COVID-19: current issues and challenges. J Clin Microbiol 58: e00512-e00520

12. Berman R, Davies A, Cooksley T et al (2020) Supportive care: an indispensable component of modern oncology [published online ahead of print, 2020 Aug 16]. Clin Oncol (R Coll Radiol) S09366555(20):30314-30319. https://doi.org/10.1016/j.clon.2020.07. 020

13. Bochennek K, Luckowitsch M, Lehrnbecher T (2020) Recent advances and future directions in the management of the immunocompromised host. Semin Oncol 47(1):40-47. https://doi.org/10. 1053/j.seminoncol.2020.02.005

14. Atkins S, He F (2019) Chemotherapy and beyond: infections in the era of old and new treatments for hematologic malignancies. Infect Dis Clin N Am 33(2):289-309. https://doi.org/10.1016/j.idc.2019. 01.001

15. Rapoport BL (2011) Management of the cancer patient with infection and neutropenia. Semin Oncol 38(3):424 430. https://doi.org/ 10.1053/j.seminoncol.2011.03.013

16. Chrysikos S, Karampitsakos T, Tzouvelekis A, Dimakou K (2018) Endobronchial metastasis from renal cell carcinoma as a reason for recurrent pulmonary infections. Adv Respir Med 86(5):245-248. https://oi.org/10.5603/ARM.2018.0039

17. Zhang GQ, Li Y, Ren YP, Fu NT, Chen HB, Yang JW, Xiao WD (2017) Outcomes of preoperative endoscopic nasobiliary drainage and endoscopic retrograde biliary drainage for malignant distal biliary obstruction prior to pancreaticoduodenectomy. World J Gastroenterol 23(29):5386-5394. https://doi.org/10.3748/wjg.v23. i29.5386

18. Smit LC, Bruins MJ, Patijn GA, Ruijs GJ (2016) Infectious complications after major abdominal cancer surgery: in search of improvable risk factors. Surg Infect 17(6):683-693. https://doi.org/10. 1089/sur.2016.033

19. Klaver CEL, Wasmann KATGM, Verstegen M, van der Bilt JDW, Nagtegaal ID, van Ramshorst B, Tanis PJ, Wolthuis AM, van Santvoort HC, de Wilt JHW, D'Hoore A (2018) Postoperative abdominal infections after resection of $\mathrm{T} 4$ colon cancer increase the risk of intra-abdominal recurrence. Eur J Surg Oncol 44(12):1880 1888. https://doi.org/10.1016/j.ejso.2018.09.016

20. Cilekar M, Erkasap S, Oner U, Akici M, Ciftci E, Dizen H, Turel S, Kavak OI, Yilmaz S (2015) An atypical cause of rapidly progressing breast lump with abscess formation: pure squamous cell carcinoma of the breast. J Cancer Res Ther 11(4):1023. https://doi.org/10.4103/0973-1482.147735

21. Tadmor T, Welslau M, Hus I (2018) A review of the infection pathogenesis and prophylaxis recommendations in patients with chronic lymphocytic leukemia. Expert Rev Hematol 11(1):57-70. https://doi.org/10.1080/17474086.2018.1407645

22. Grever MR, Abdel-Wahab O, Andritsos LA, Banerji V, Barrientos J, Blachly JS, Call TG, Catovsky D, Dearden C, Demeter J, Else M, Forconi F, Gozzetti A, Ho AD, Johnston JB, Jones J, Juliusson G,
Kraut E, Kreitman RJ, Larratt L, Lauria F, Lozanski G, Montserrat E, Parikh SA, Park JH, Polliack A, Quest GR, Rai KR, Ravandi F, Robak T, Saven A, Seymour JF, Tadmor T, Tallman MS, Tam C, Tiacci E, Troussard X, Zent CS, Zenz T, Zinzani PL, Falini B (2017) Consensus guidelines for the diagnosis and management of patients with classic hairy cell leukemia. Blood 129(5):553560. https://doi.org/10.1182/blood-2016-01-689422

23. Morrison VA (2014) Infections in patients with leukemia and lymphoma. Cancer Treat Res 161:319-349. https://doi.org/10.1007/ 978-3-319-04220-6 11

24. Walsh TJ, Gamaletsou MN (2013) Treatment of fungal disease in the setting of neutropenia. Hematol Am Soc Hematol Educ Program 2013:423-427. https://doi.org/10.1182/asheducation2013.1.423

25. Klastersky J, de Naurois J, Rolston K, Rapoport B, Maschmeyer G, Aapro M, Herrstedt J, ESMO Guidelines Committee (2016) Management of febrile neutropaenia: ESMO Clinical Practice Guidelines. Ann Oncol 27(suppl 5):v111-v118

26. Knight T, Ahn S, Rice TW, Cooksley T (2017) Acute oncology care: a narrative review of the acute management of neutropenic sepsis and immune-related toxicities of checkpoint inhibitors. Eur J Intern Med 45:59-65

27. Horita N, Shibata Y, Watanabe H, Namkoong H, Kaneko T (2017) Comparison of antipseudomonal $\beta$-lactams for febrile neutropenia empiric therapy: systematic review and network meta-analysis. Clin Microbiol Infect 23(10):723-729. https://doi.org/10.1016/j.cmi. 2017.03.024

28. Paul M, Dickstein Y, Schlesinger A, Grozinsky-Glasberg S, Soares-Weiser K, Leibovici L (2013) Beta-lactam versus betalactam-aminoglycoside combination therapy in cancer patients with neutropenia. Cochrane Database Syst Rev 2013(6): CD003038. https://doi.org/10.1002/14651858

29. Bliziotis IA, Michalopoulos A, Kasiakou SK, Samonis G, Christodoulou C, Chrysanthopoulou S, Falagas ME (2005) Ciprofloxacin vs an aminoglycoside in combination with a betalactam for the treatment of febrile neutropenia: a meta-analysis of randomized controlled trials. Mayo Clin Proc 80(9):1146-1156. https://doi.org/10.4065/80.9.1146

30. Klastersky J, Paesmans M (2013) The Multinational Association for Supportive Care in Cancer (MASCC) risk score: 10 years of use for identifying low risk neutropenic cancer patients. Support Care Cancer 21:1487-1495

31. Teuffel O, Ethier M, Alibhal S et al (2011) Outpatient management of cancer patients with febrile neutropenia: a systematic review and meta-analysis. Ann Oncol 22:2358-2365

32. Cooksley T, Holland M, Klastersky J (2015) Ambulatory outpatient management of patients with low risk febrile neutropaenia. Acute Med 14(4):178-181

33. Klastersky J, Paesmans M, Rubenstein EB, Boyer M, Elting L, Feld R, Gallagher J, Herrstedt J, Rapoport B, Rolston K, Talcott J (2000) The Multinational Association for Supportive Care in Cancer risk index: a multinational scoring system for identifying low-risk febrile neutropenic cancer patients. J Clin Oncol 18(16):3038-3051. https://doi.org/10.1200/JCO.2000.18.16.3038

34. Taplitz RA, Kennedy EB, Bow EJ, Crews J, Gleason C, Hawley DK, Langston AA, Nastoupil LJ, Rajotte M, Rolston K, Strasfeld L, Flowers CR (2018) Outpatient Management of Fever and Neutropenia in Adults Treated for Malignancy: American Society of Clinical Oncology and Infectious Diseases Society of America Clinical Practice Guideline Update. J Clin Oncol 36(14):14431453. https://doi.org/10.1200/JCO.2017.77.6211

35. Ahn S, Rice TW, Yeung SJ, Cooksley T (2018) Comparison of the MASCC and CISNE scores for identifying low risk neutropenic fever patients: analysis of data from three emergency departments in cancer centers in three continents. Support Care Cancer 26(5): $1465-1470$ 
36. Lasserson DS, Harris C, Elias T, Bowen J, Clare S (2018) What is the evidence base for ambulatory care for acute medical illness? Acute Med 17(3):148-153

37. Hamad M, Connolly V (2018) Ambulatory emergency care - improvement by design. Clin Med 18(1):69-74

38. Cooksley T, Campbell G, Al-Sayed T, Lamola L, Berman R (2018) A novel approach to improving ambulatory outpatient management of low risk febrile neutropenia: an Enhanced Supportive Care (ESC) Clinic. Support Care Cancer 26(9):2937-2940

39. Marshall W, Campbell G, Knight T, Al-Sayed T, Cooksley T (2020) Emergency ambulatory management of low-risk febrile neutropenia: multinational association for supportive care in cancer fits-real-world experience from a UK cancer center. J Emerg Med 58(3):444-448

40. Marshall E (2019) Ambulatory management in low risk neutropenic sepsis - a plea for integrated acute cancer care. Acute Med 18(1):5-6

41. Wang L, Baser O, Kutikova L, Page JH, Barron R (2015) The impact of primary prophylaxis with granulocyte colonystimulating factors on febrile neutropenia during chemotherapy: a systematic review and meta-analysis of randomized controlled trials. Support Care Cancer 23(11):3131-3140. https://doi.org/10. 1007/s00520-015-2686-9

42. Smith TJ, Bohlke K, Lyman GH, Carson KR, Crawford J, Cross SJ, Goldberg JM, Khatcheressian JL, Leighl NB, Perkins CL, Somlo G, Wade JL, Wozniak AJ, Armitage JO (2015) American Society of Clinical Oncology. Recommendations for the use of WBC growth factors: American Society of Clinical Oncology Clinical Practice Guideline Update. J Clin Oncol 33(28):3199-3212. https://doi.org/10.1200/JCO.2015.62.3488

43. Lyman GH (2006) Chemotherapy dose intensity and quality cancer care. Oncology (Williston Park) 20(14 Suppl 9):16-25

44. Ricotta R, Cerea G, Schiavetto I, Maugeri MR, Pedrazzoli P, Siena S (2006) Pegfilgrastim: current and future perspectives in the treatment of chemotherapy-induced neutropenia. Future Oncol 2(6): 667-676. https://doi.org/10.2217/14796694.2.6.667

45. Egan G, Robinson PD, Martinez JPD, Alexander S, Ammann RA, Dupuis LL, Fisher BT, Lehrnbecher T, Phillips B, Cabral S, Tomlinson G, Sung L (2019) Efficacy of antibiotic prophylaxis in patients with cancer and hematopoietic stem cell transplantation recipients: a systematic review of randomized trials. Cancer Med 8(10):4536-4546. https://doi.org/10.1002/cam4.2395

46. Rapoport B, Klastersky J, Raftopoulos H, Freifeld A, Aoun M, Zinner SH, Rolston KV (2016) The emerging problem of bacterial resistance in cancer patients; proceedings of a workshop held by MASCC "Neutropenia, Infection and Myelosuppression" Study Group during the MASCC annual meeting held in Berlin on 2729 June 2013. Support Care Cancer 24(7):2819-2826. https://doi. org/10.1007/s00520-016-3183-5

47. Supportive care strategies during the COVID-19 pandemic. https:// www.esmo.org/guidelines/cancer-patient-management-during-thecovid-19-pandemic/supportive-care-in-the-covid-19-era (Accessed 21-July-2020)

48. COVID-19 patient care information. Available at: https://www. asco.org/asco-coronavirus-information/care-individuals-cancerduring-covid-19 (Accessed 21-July-2020)
49. ASCO Special report: a guide to cancer care delivery during the COVID-19 pandemic. May 19, 2020. Available from: https:/www. asco.org/sites/new-www.asco.org/files/content-files/2020-ASCOGuide-Cancer-COVID19.pdf (Accessed 21-July-2020)

50. Hematopoietic growth factors short-term recommendations specific to issues with COVID-19 (SARS-CoV-2) https://www.ncen.org/ covid-19/pdf/HGF_COVID-19.pdf (Accessed 21-July-2020)

51. Neutropenic sepsis: prevention and management of neutropenic sepsis in cancer patients. Evidence review, search strategies, health economics evidence review and health economics plan: developed for NICE by the National Collaborating Centre for Cancer 2012. UK - NICE. Available from: www.nice.org.uk > evidence-review188303582 (Accessed 21-July-2020)

52. Basch E, Deal AM, Kris MG, Scher HI, Hudis CA, Sabbatini P, Rogak L, Bennett AV, Dueck AC, Atkinson TM, Chou JF, Dulko D, Sit L, Barz A, Novotny P, Fruscione M, Sloan JA, Schrag D (2016) Symptom monitoring with patient-reported outcomes during routine cancer treatment: a randomized controlled trial. J Clin Oncol 34(6):557-565

53. Basch E, Deal AM, Dueck AC, Scher HI, Kris MG, Hudis C, Schrag D (2017) Overall survival results of a trial assessing patient-reported outcomes for symptom monitoring during routine cancer treatment. JAMA 318(2):197-198

54. Scotté F, Oudard S, Aboudagga H, Elaidi R, Bonan B (2013) A practical approach to improve safety and management in chemotherapy units based on the PROCHE - Programme for optimisation of the chemotherapy network monitoring program. Eur J Cancer 49:541-544

55. Scotté F, Minvielle E, Mir O, André F, Barlesi F, Soria JC (2020) A patient reported outcome platform, a useful tool to improve monitoring and effective management of Covid-19-positive patients with cancer. Eur J Cancer 132:1-4. https://doi.org/10.1016/j.ejca.2020. 03.020

56. Hollander JE, Carr BG (2020) Virtually perfect? Telemedicine for COVID-19. N Engl J Med 382:1679-1681

57. Cooksley T, Marshall W, Ahn S, Lasserson DS, Marshall E, Rice TW, Klotz A (2020) Ambulatory emergency oncology: a key tenet for future emergency oncology care. Int J Clin Pract 74(1):e13436

58. Ahn S, Cooksley T, Banala S, Buffardi L, Rice TW (2018) Validation of the EPIPHANY index for predicting risk of serious complications in cancer patients with incidental pulmonary embolism. Support Care Cancer 26(10):3601-3607

59. Font C, Fernandez-Avilés F, Calderon $\mathrm{C}$ et al (2016) Home management of acute medical complications in cancer patients. Support Care Cancer 24(5):2129-2137

60. Handley NR, Bekelman JE (2019) The oncology hospital at home. J Clin Oncol 37:448-452

61. Marron JM, Joffe S, Jagsi R, Spence RA, Hlubocky FJ (2020) Ethics and resource scarcity: ASCO recommendations for the oncology community during the COVID-19 pandemic. J Clin Oncol 38(19):2201-2205. https://doi.org/10.1200/JCO.20.00960

Publisher's note Springer Nature remains neutral with regard to jurisdictional claims in published maps and institutional affiliations. 